\title{
Urodimento
}

REVISTA DE ESTUDOS EM ARTES CÊNICAS

E-ISSN 2358.6958

\section{Petformances - Arte relacional como poéticas do cuidado para/com/por animais}

Tania Alice

Para citar este artigo:

ALICE, Tania. Petformances - Arte relacional como poéticas do cuidado para/com/por animais. Urdimento Revista de Estudos em Artes Cênicas, Florianópolis, v. 2, n. 41, set. 2021.

do) DOI: http:/dx.doi.org/10.5965/1414573102412021e0125

Este artigo passou pelo Plagiarism Detection Software | iThenticate 


\title{
Resumo
}

O artigo propõe cultivar os encantos e as forças de vida por meio da criação de performances com, para e por animais, chamadas "petformances", linguagem artística do campo da performance, que comecei a desenvolver durante a pandemia em parceria com o cachorro Buda, do qual sou tutora. Descreve de forma cartográfica o processo que conduziu a experimentação desse tipo de performance relacional em tempos de distanciamento social, focalizando os aprendizados profundos trazidos pelos animais e as possibilidades de multiplicação dessas práticas, por meio de cursos e oficinas, em uma perspectiva que descentraliza a visão do humano e valoriza a criatividade dos animais.

Palavras-chaves: Petformance. Arte relacional. Animais. Natureza.

\section{Relational Art as Arts of Care for, with and by animals e Petformances}

\begin{abstract}
The paper proposes to cultivate the charms and the forces of life through the creation of performances with, for and by animals, called "petformances", artistic language of the performance field, which I started to develop during the pandemic in partnership with my dog Buda. Cartographically describes the process that led to the experimentation of this type of relational performance in times of social distance, focusing on the deep learning brought by animals and the possibilities of multiplying these practices, through courses and workshops, in a perspective that decentralizes the vision of the human and values the creativity of animals.
\end{abstract}

Keywords: Petformance. Relational art. Animals. Nature.

\section{Arte relacional como poética del cuidado de, con e por animales}

\section{Resumen}

El artículo propone cultivar los encantos y las fuerzas de la vida a través de la creación de performances con, para y por animales, llamadas "petformances", lenguaje artístico del campo de la performance, que comencé a desarrollar durante la pandemia en sociedad con mi perro Buda. Describe cartográficamente el proceso que llevó a la experimentación de este tipo de actuación relacional en tiempos de distancia social, enfocándose en el aprendizaje profundo que traen los animales y las posibilidades de multiplicar estas prácticas, a través de cursos y talleres, en una perspectiva que descentraliza la visión de lo humano y valora la creatividad de los animales.

Palabras clave: Petformance. Arte relacional. Animales. Naturaleza.

${ }^{1}$ Professora de Atuação Cênica (performance) da Universidade Federal do Estado do Rio de Janeiro (UNIRIO), onde leciona e orienta projetos de criação na Graduação e na Pós-Graduação (Mestrado e Doutorado). taniaalice@hotmail.com 
O contrário da vida não é a morte, é o desencanto.

(Simas/Rufino)

Como exercício pessoal, para me manter atenta aos encantos, há alguns meses comecei a registrar, diariamente, em vídeos de um segundo, as belezas do meu dia. Ao final de cada mês, reúno o material e edito os meus encantos. Por vezes, não estou com o celular à mão. Por vezes, o encanto se esvaece antes que eu consiga abrir a câmera, como foi com o bando de dez quatis que avistei em uma cachoeira, ontem, passeando por Santa Teresa, na cidade do Rio de Janeiro. Porém, às vezes, seja por treino ou por sorte, consigo capturar o encanto e, revendo os vídeos, percebo que - apesar de perda, dor, sofrimento e distanciamento social - todos os dias, semanas e meses têm seus encantamentos.

Durante a pandemia, minha prática espiritual tem sido me manter atenta para ver, cuidar e até provocar encantos. Assistindo ao conjunto de vídeos, percebi que grande parte deles são produzidos por nosso cachorro, Buda, acolhido no início da pandemia, talvez, por intuir que naquele momento se anunciava um período de permanência em casa - que nunca pensamos ser tão longo - e que a ausência de deslocamentos para festivais, apresentações ou eventos artístico-científicos permitiria uma presença mais dedicada nos primeiros meses de vida dele.

Buda chegou aos 2 meses de idade, no dia 5 de junho de 2020 e após quase um ano de convivência com ele, posso dizer que diariamente ele me ensina o que é essencial: presença, silêncio, tempo desmedido para o carinho e o amor, disposição constante para a brincadeira, alegria com coisas simples (como uma meia encontrada dentro de um sapato), consciência da impermanência e outros detalhes fundamentais da vida feliz, como estar atento ao local onde se guarda a comida, nunca recusar um passeio, procurar algo até encontrá-lo e, principalmente, o amor incondicional, do qual emerge toda forma de criatividade.

Não há tempo feio para um cão. Todo dia é dia de passeio e de muitas possibilidades. Nessa perspectiva, que compartilho há 10 meses, Buda me ensinou a deslocar o olhar e a ficar atenta à todas as formas de manifestação da vida. Entender o ponto de vista dele tem se mostrado como um sossego em tempos 
difíceis, mas também, uma forma de cura. A relação com a possibilidade iminente da alegria, que emerge da relação, é uma cura constante, uma forma de saúde. É sobre esse encontro amoroso, criativo - também chamado petformance - que gostaria de falar aqui.

\section{Deslocamentos perceptivos: descentralizando o humano}

Em março de 2020, foi decretada oficialmente a pandemia da Covid-19 no Brasil. Em seu livro “A vida não é útil”, Ailton Krenak (2020, p. 17) mostra que a atual crise sanitária, política e econômica, antes de tudo, é ecológica. Ela é o resultado daquilo que ele chama de nosso "vício de Modernidade" e que nos confere ilusoriamente a sensação de poder, de permanência, a ilusão de que vamos continuar existindo indefinidamente. Para Krenak (2020, p. 11), "É incrível que esse vírus que está aí agora esteja atingindo só as pessoas. Foi uma manobra fantástica do organismo da Terra de tirar a teta da nossa boca e dizer: Respirem agora, eu quero ver".

Como prática de cuidado e de saúde, Krenak (2020) propõe deslocar nosso ponto de vista do foco humano e restituir em nós a consciência da sabedoria da natureza e de todas as formas de vida.

\footnotetext{
A vida é esse atravessamento do organismo vivo do planeta numa dimensão imaterial. Em vez de ficarmos pensando no organismo da Terra respirando, o que é muito difícil, pensemos na vida atravessando montanhas, galerias, rios, florestas. [...].

Assim como existem as palavras "vento", "fogo", "água", as pessoas acham que pode haver a palavra "vida", mas não. Vida é transcendência, está para além do dicionário, não tem definição (Krenak, 2020, p.29).
}

Essa visão, que restitui a primazia da natureza acima da visão cientificista do homem branco cis colonizador, cujas práticas conduziram à crise que vivemos atualmente, é abordada por Kaka Werá Jecupé (1998) em seu livro "A terra dos mil povos: História indígena do Brasil contada por um índio”. Nessa narrativa, o autor apresenta uma visão da história baseada em outras concepções de tempo e espaço, diferentes das tradicionalmente veiculadas pela cultura dominante, 
afirmando que muitos dos mitos fundadores se originam na natureza e não em alguma invenção ou marco humano: "Há tribos que começam sua história desde quando o clã era formado por seres do espírito das águas, outras trazem sua memória animal como início da história, e há aquelas que iniciam sua história a partir da árvore que foram" (Jecupé, 1998, p.20).

Essa visão se situa em um contexto de revisão dos critérios fundantes do pensamento colonizador, que sempre coloca o "outro" como subalterno em relação à um pensamento dominante padrão. Estamos no momento de poder ver mais que o universo, percebendo pluriversos, onde as diversidades - sejam raciais, de gênero, de corpo, mente ou de formas de vida - possam ser ouvidas e respeitadas como legítimas e complementares. O filósofo Charles Feitosa (2011), no capítulo $\mathrm{O}$ silêncio dos animais, de seu livro Nietzsche/Deleuze Natureza/Cultura, corrobora essa visão:

As relações dos viventes humanos com os viventes não-humanos são violentas e precisam mudar. Será preciso reavaliar nossa responsabilidade ética diante de nossos vizinhos na terra: ficar atento, de um lado, para a pluralidade irredutível dos animais e de outro lado, para a dimensão animal que há no corpo de cada um de nós (Feitosa, 2011, p. 96).

Nesse contexto, o que pode me ensinar Buda, o meu cachorro? Em "O que os animais nos ensinam sobre política”, Brian Massumi (2017), filósofo e pesquisador canadense, aprofunda a crítica da visão antropocentrista, mostrando que as diferentes formas de inteligência e de criatividade não são características exclusivas da humanidade. Ao contrário do que poderíamos pensar, a criatividade está na natureza e o humano, simplesmente, faz parte dela.

A esperança é que no decorrer da investigação possamos ir além de nosso antropomorfismo quanto a nós mesmos: nossa imagem de nós mesmos como estando humanamente apartados dos outros animais; nossa inveterada vaidade no que se refere à nossa assumida identidade de espécie, baseada em razões especulativas de nossa exclusiva propriedade sobre linguagem, pensamento e criatividade (Massumi, 2017, p.14).

Em outras palavras: quando estamos atribuindo à natureza, e 
especificamente aos animais, capacidades como criatividade ou inteligência, não estamos praticando um antropomorfismo básico, ao contrário, estamos deixando de lado nossa arrogância humana.

Em seu ensaio, Massumi (2017, p.79) enumera os múltiplos ganhos que podemos ter ao aceitarmos esse deslocamento do olhar. Dentre eles, há uma característica que me toca muito e que ele qualifica de "excesso lúdico": uma disposição que nos faz considerar a vida como algo a ser brincado e não como algo útil. Visão, por vezes, difícil de ser trazida para contextos profissionais, que, em suas estruturas, tendam à identificação com uma suposta necessidade de seriedade, que, muitas vezes, não se mostra conectada com o aprofundamento as nossas potências de vida, de alegria e de compaixão.

\section{Tentativas de preservar o encanto}

Retorno ao tempo histórico em que foi decretada a pandemia no Brasil. Em um primeiro momento, estarrecida e ainda sob estado de choque, parei para repensar a minha prática sob o ângulo de possíveis multiplicações. Ao longo dos últimos 10 anos, tenho me empenhado em desenvolver - junto às/aos pesquisadoras/es do Grupo de Pesquisa "Práticas Performativas Contemporâneas" e ao Coletivo Performers sem Fronteiras ${ }^{2}$, vinculado a esse grupo de pesquisa projetos artísticos participativos que podem ser produtores de felicidade.

Coletar gargalhadas em um prédio de uma periferia violenta da cidade de Marseille; ir de casa em casa para dançar a música preferida do/a morador/a em sua cozinha e em seguida reunir todas as pessoas para uma festa onde essas músicas são tocadas; coletar abraços de 5, 10 ou 15 minutos, no Brasil, para depois levá-los à vítimas de terremotos no Nepal; criar salas de aula a céu aberto, onde cada um, em cinco minutos, pode ensinar aos outros o que é essencial para ele são algumas das 21 ações artísticas que reuni em um livro intitulado "Manual para performers e não-performers - 21 ações artísticas para produzir felicidade”. Esse

${ }^{2}$ Cf. disponível em: www.performerssemfronteiras.com e @performerssemfronteiras. 
livro, escrito durante os três primeiros meses da pandemia, tem por ideia norteadora a multiplicação da produção de felicidade ${ }^{3}$. A fundamentação dessa prática da multiplicação é apresentada no artigo "O re-enactment como prática pedagógica no Brasil"4. Refazendo performances, as pessoas entendem as possibilidades dessa linguagem, fazem suas próprias leituras e adaptações e, com o tempo, aprendem as suas especificidades, para em seguida criarem suas próprias ações. Com essa publicação, pretendia recuperar o tempo perdido, assim que acabasse a pandemia, realizando as diferentes ações poéticas participativas em ruas, prédios, bairros, periferias e espaços urbanos.

O livro foi publicado em 2021 e a pandemia continuou ${ }^{5}$. No contexto de um governo que promove uma política genocida por meio de criminosa desinformação, com enorme atraso nas compras de vacinas e uma produção de mentiras envolvendo saúde pública, após um ano de pandemia, é eticamente impossível trabalhar com performances do encontro. Aquilo que Bourriaud (2009) chama Estética Relacional, que Kester (2004) nomeia Conversation Pieces e que para as pesquisadoras Suzi Weber e Renata Teixeira são Performances do Encontro ${ }^{6}$ tornou-se impossível de ser vivido em um contexto em que, por crime e omissão do governo do Brasil, chega-se a 3000 mortes por dia e as variantes do vírus, resultado da prática da necropolíticaª (Mbembe, 2018) governamental, se multiplicam rapidamente.

Sendo assim, uma das perguntas que me fiz nesse período crítico foi: Que encontros geradores de potências de vida e de saúde são possíveis em tempos de pandemia? Como pesquisadora em artes, realizei diversas tentativas. Criei um grupo no Facebook intitulado "Performance durante a quarentena" com mais de

${ }^{3}$ Esse livro propõe 21 programas performativos de ações participativas que geram felicidade, que podem ser multiplicados pela/os leitora/es, de maneira a gerar felicidade.

${ }^{4}$ Refiro-me ao artigo "O re-enactment como prática pedagógica no Brasil", disponível em: Tania Alice, 2016. Esse artigo explicita o quanto refazer uma ação performática tem um impulso criativo e pedagógico para quem se dispõe para tal.

${ }^{5}$ O livro, com prefácio de Rita von Hunty, personagem drag do ex-aluno da UNIRIO, Gui Terreri, está disponível em: www.editoramultifoco.com

${ }^{6}$ Cf. Mestrado de Renata Teixeira Ferreira da Silva, orientado pela Profa. Dra. Suzanne Weber da Silva, intitulado: Performances do Encontro: práticas performativas em tempos de presença real e virtual Universidade Federal do Rio Grande do Sul, 2020.

A expressão "necropolítica" foi cunhada pelo filósofo camaronês Achille Mbembe em livro com título homônimo (São Paulo: 2018, n-1 edições). 
1500 participantes, que se revezavam para realizar desafios performáticos semanais; idealizei o curso "Performances possíveis em tempos de pandemia", oferecido para alunas/os da graduação da UNIRIO, que pretendia a exploração do campo pessoal, familiar e da própria casa; idealizei e dirigi, junto aos Performers sem Fronteiras, o espetáculo "Crescer pra Passarinho - uma experiência de cuidados poéticos online". . O espetáculo foi apresentado mais de oitenta vezes durante a pandemia para profissionais de saúde que atuam na linha de frente do combate à Covid-19 e, em seguida, foi realizado com o objetivo de arrecadar fundos para a compra de cestas básicas, em apoio à ação realizada pela Associação de Produtores Teatrais do Rio de Janeiro - APTR. Essa última experiência, criada especificamente para o formato online, que também almeja um devir pássaro para voar em tempos de enclausuramento, merece um artigo específico/

A experiência do "Crescer pra passarinho" me tirou um pouco da sensação que eu tive durante minhas diversas aulas ou peças de que eu estava, artisticamente, "dando um jeito": um pouco como se eu estivesse tentando fazer um bolo sem os ingredientes principais, no caso da linguagem artística que eu trabalho, sem o encontro presencial, que é o meio e fim desse tipo de linguagem. Tanto que as oficinas de petformances só podem acontecer de forma virtual: primeiro, porque seria impossível deslocar os animais, tanto por conta do estresse do deslocamento como por conta da convivência impossível, depois porque os animais necessitam estar em seus lares, confiantes, para poder se desenvolver criativamente. Durante longas horas em frente à janela, na impossibilidade de encontrar meus parceiros de trabalho há mais de 10 anos, ficava indagando tristemente como e com quem eu poderia ter as experiências de criação compartilhada que dão sentido à vida. Um dia, enquanto estava meditando sobre essa questão, senti um focinho quente no meu colo. A presença silenciosa e atenta que nos ensina o essencial. Olhei de volta para Buda e o convidei para performar.

${ }^{8}$ O elenco do espetáculo conta com o Prof. Dr. Gilson Motta (UFRJ); as/os alunas/os de Iniciação Científica Anderson Caetano (IC/FAPERJ), Gizelly de Paula (IC-UNIRIO) e Gabriela Estolano (IC-UNIRIO); as/os orientandas/os de Mestrado Ivan Faria, Ana Paula Penna e, inicialmente, Ana Raquel Machado e Marianna Rego; o aluno voluntário Marcelo Miguez e, inicialmente, também com o aluno Gabriel Hippólito. 


\section{"Ativar e expandir o saber ecoetológico ao longo da vida" (Suely Rolnik) ou "Petformances" ou "O que Buda me ensinou"}

Como forma de experimentação inicial, resolvi realizar junto com Buda algumas das obras que compõem a história da performance, me dispondo a incluir as possivveis transformações que ele poderia fazer nessas performances icônicas. Para esse trabalho, a linguagem da fotoperformance se tornou uma evidência por ser uma "tentativa de capturar o sensível", conforme define Moacir Junior (2019). Então, nós realizamos, entre outras, o re-enactment das seguintes performances: Parangolés, Hélio Oiticia; A artista está presente, Marina Abramovic; Cut Piece, Yoko Ono; Como explicar arte contemporânea para uma lebre morta, Joseph Beuys; Bed In, Yoko Ono e John Lennon; Antropometrias, Yves Klein; Paradox of Praxis, Francis Alys; Reciprocidade desalmada, Thales Frey; Silhuetas, Ana Mendieta; Merda de Artista, Piero Manzoni; Marca Registrada, Leticia Parente; One year performance Project, Tehching Hsieh (1983-1984, com Linda Montano); Dropping a Han Dinasty Urn, Ai Weiwei; Action Painting, Pollock; Circles, Richard Long; Dinheiro acaba, Paulo Nazareth; A inusitada orquestra de legumes e verduras de Viena, Matthias Meinharter; Cegos, o Desvio Coletivo/Coletivo Pi; Dog, Oleg Kulig; The Bed Project (minha autoria); Divisor, Lygia Pape; My little me, Anja Carr; Objetos relacionais, Lygia Clark; todas disponíveis no Instagram de @buda_performer. Nesses momentos, que foram como brincadeiras diárias, percebi o quão possível é criar cumplicidade num contexto divertido dentro de casa e como o próprio Buda podia sugerir e provocar mudanças nos programas performativos, inicialmente propostos. 
Figura 1 - O cachorro está presente

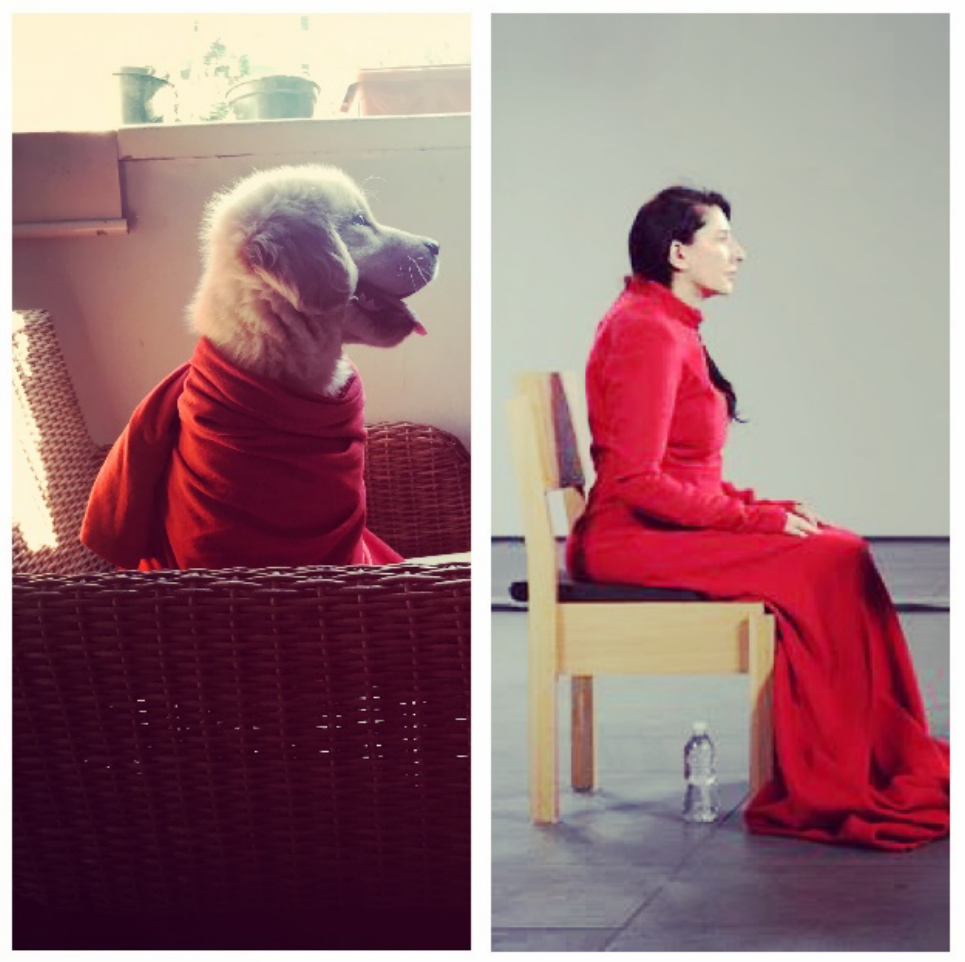

Arquivo Tania Alice, 2020.

Figura 2 - Destruindo um pote de petiscos
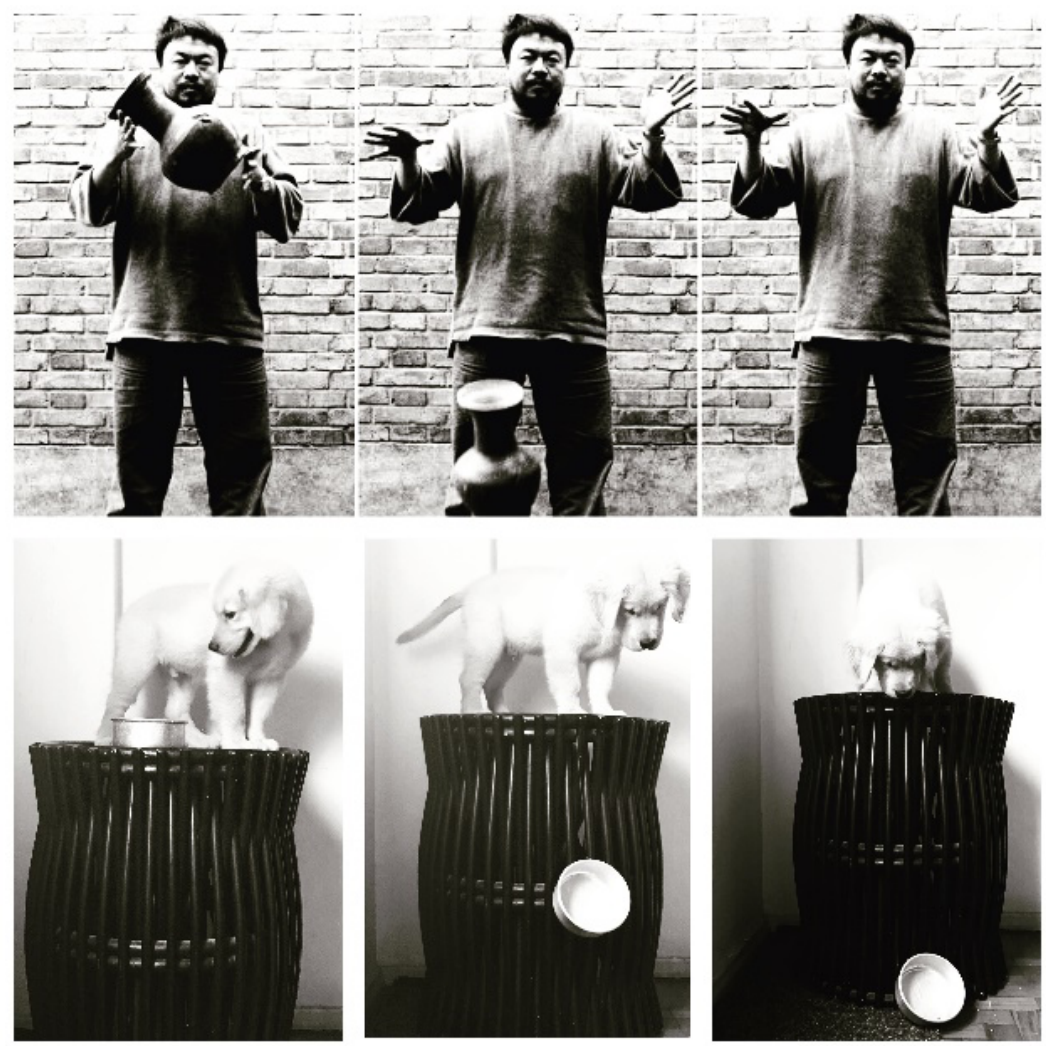

Arquivo Tania Alice, 2020. 
Figura 3 - Cachorromorfismos

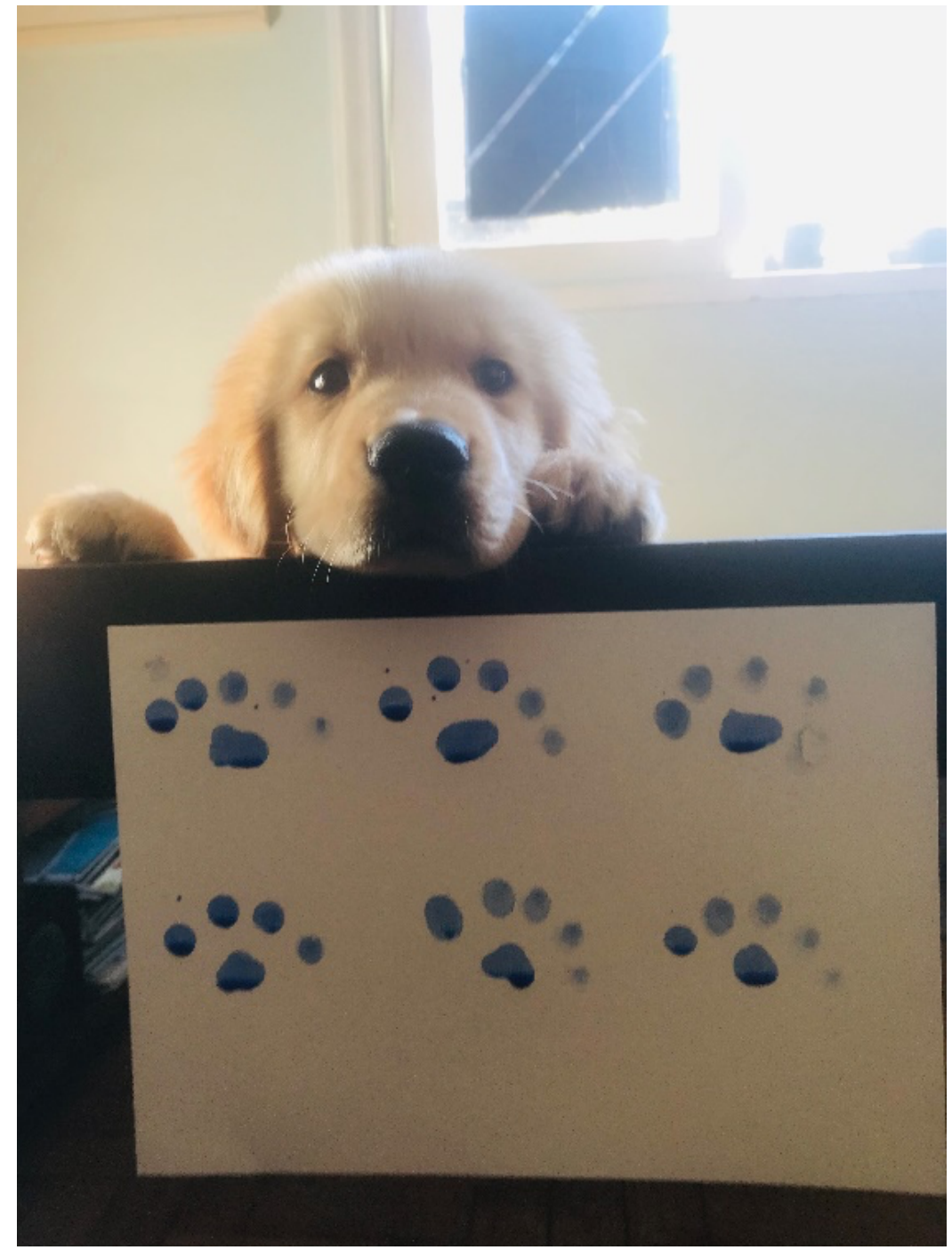

Arquivo Tânia Alice, 2020.

Dos primeiros experimentos, aos poucos, emergiam outras experiências propostas por Buda, como a fotoperformance "Coisas que meu cachorro traz pra mim", que reúne todos os objetos que diariamente ele traz até a minha mesa de trabalho; a experimentação "Escritos sobre o meu cão"; a performance "Como tristeza", na qual Buda devora a palavra Tristeza, composta por petiscos; e a sua campanha política a favor da eleição de Guilherme Boulos (PSOL, 2020) para a Prefeitura de São Paulo. 
Figura 4 - Coisas que meu cachorro traz pra mim Arquivo Tania Alice, 2020.
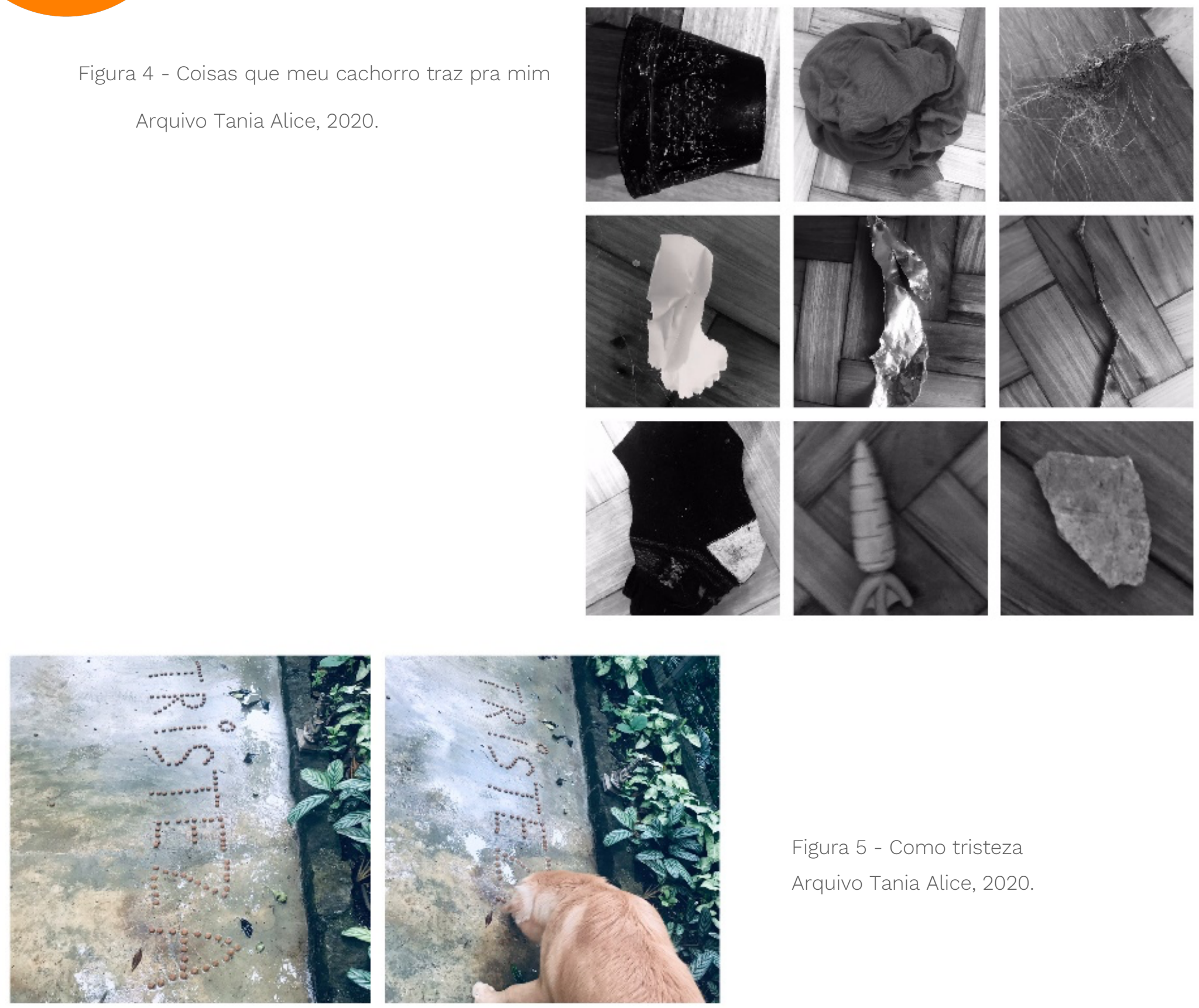

Figura 5 - Como tristeza

Arquivo Tania Alice, 2020.
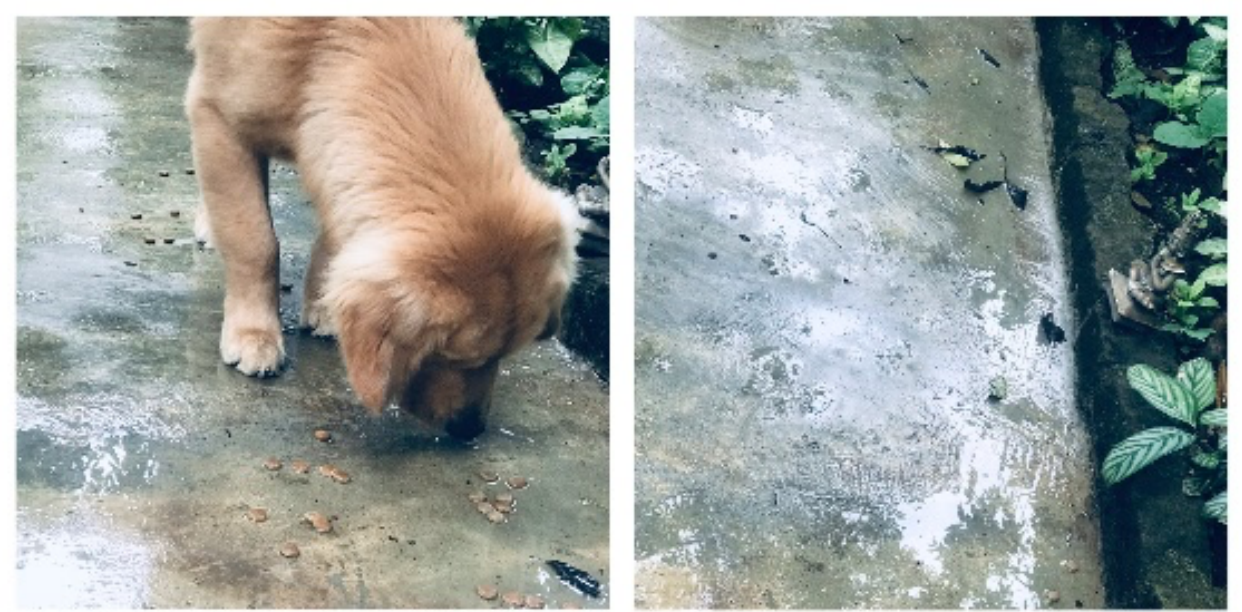

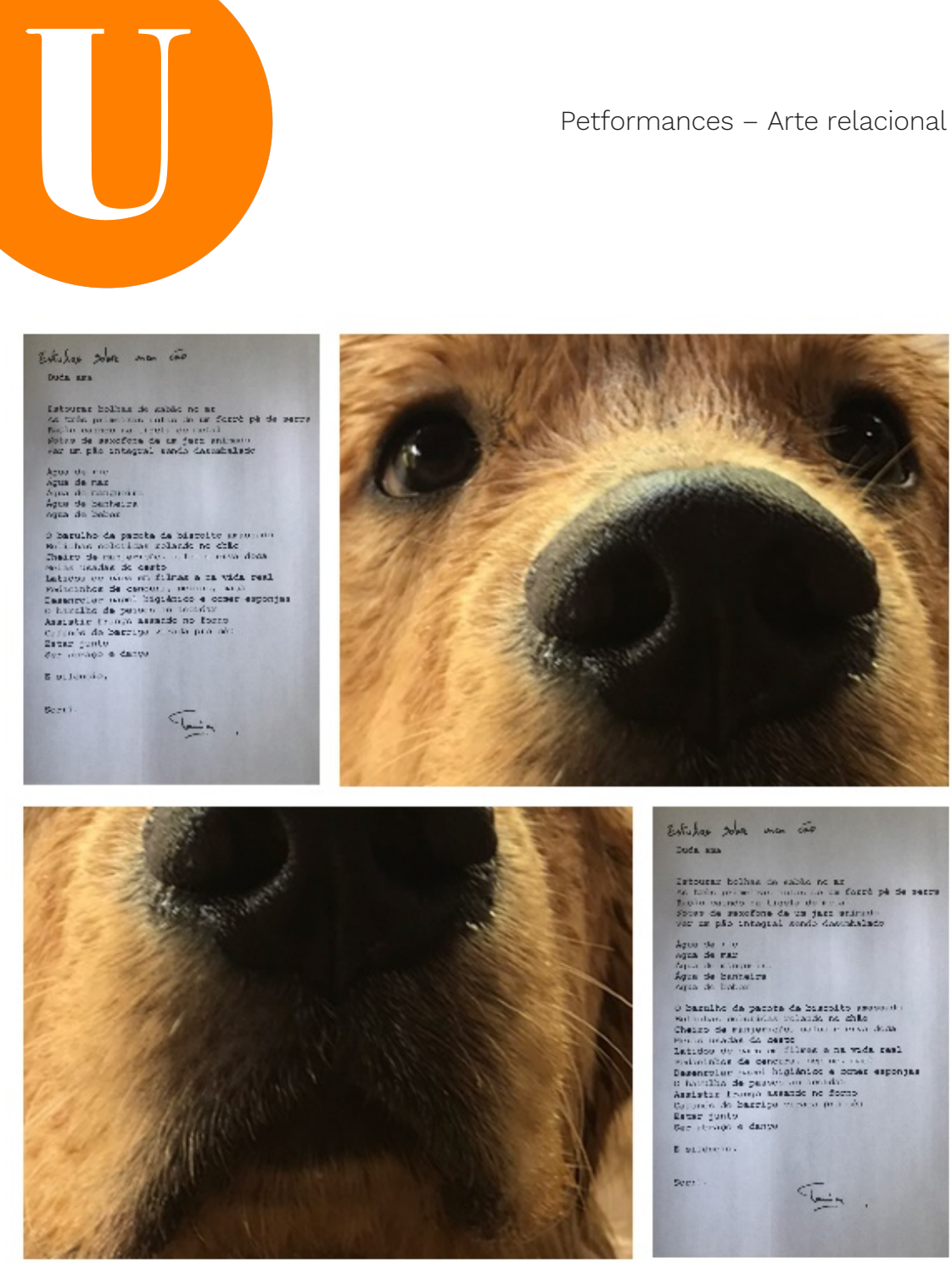

Figura 7 - Campanha política de Buda a favor de Boulos

Arquivo Tania Alice, 2020.

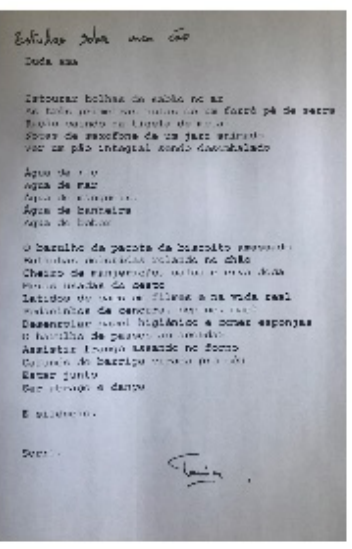

Petformances - Arte relacional como poéticas do cuidado para/com/por animais

Tania Alice
Figura 6 - Escritos

Arquivo Tania Alice, 2020.

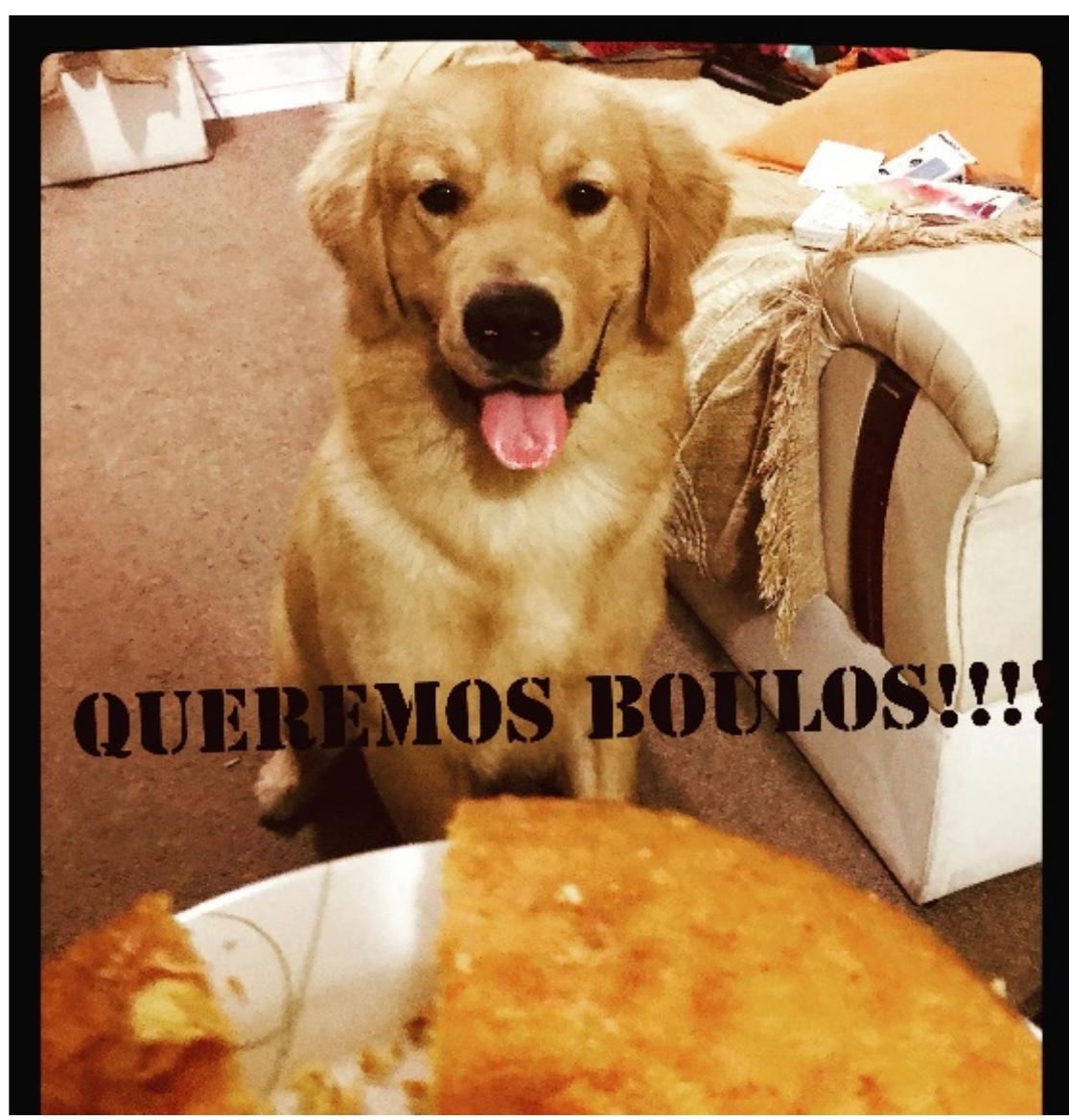


Quando em uma Live me perguntaram se eu estava fazendo performance, respondi brincando que estava fazendo "Petformance" com meu cachorro e, assim, aquilo que era inicialmente uma brincadeira e uma tentativa de driblar as angústias da pandemia, acabou se tornando um conceito de performance relacional a ser explorado. Com o desejo de expandir a alegria de "petformar" com Buda e de intensificar a pesquisa nessa arte, criei um curso intitulado "Petformance - poéticas do cuidado com animais" e convidei a médica veterinária e aluna de Artes Cênicas da UNIRIO, Manuela Mellão, para ser monitora da disciplina. Seu olhar clínico e comportamental, mas também holístico e integrativo, foi fundamental para o aprofundamento da pesquisa e, a partir dessa primeira experiência, foi se construindo uma parceria.

Realizado remotamente durante o primeiro semestre de 2020, o curso foi muito bem recebido pelas/os alunas/os e suas/seus parceiras/os animais a ponto de novamente ser oferecido para a graduação da Escola de Teatro da UNIRIO, no primeiro semestre de 2021. Em conjunto, desenvolvemos uma oficina de curta duração, cujo primeiro compartilhamento aconteceu na Mostra Internacional de Teatro - MIT de São Paulo, nos dias 18 e 19 de março de 2021, com um retorno muito comovente por parte da/os participantes, que produziram, junto com seus pets, obras extremamente potentes: releituras, composições, escritas criativas, fotografias 9 ... Nesse contexto, um dos exercícios, inspirado no filme "Professor Polvo", consistiu em enumerar coletivamente o que aprendemos com nossos animais. Abaixo, gráfico que sintetiza as respostas das/dos participantes do curso:

${ }^{9}$ A oficina também permitiu perceber que há um grande interesse por parte dos participantes, pois para 20 vagas, tivemos 297 inscrições. 


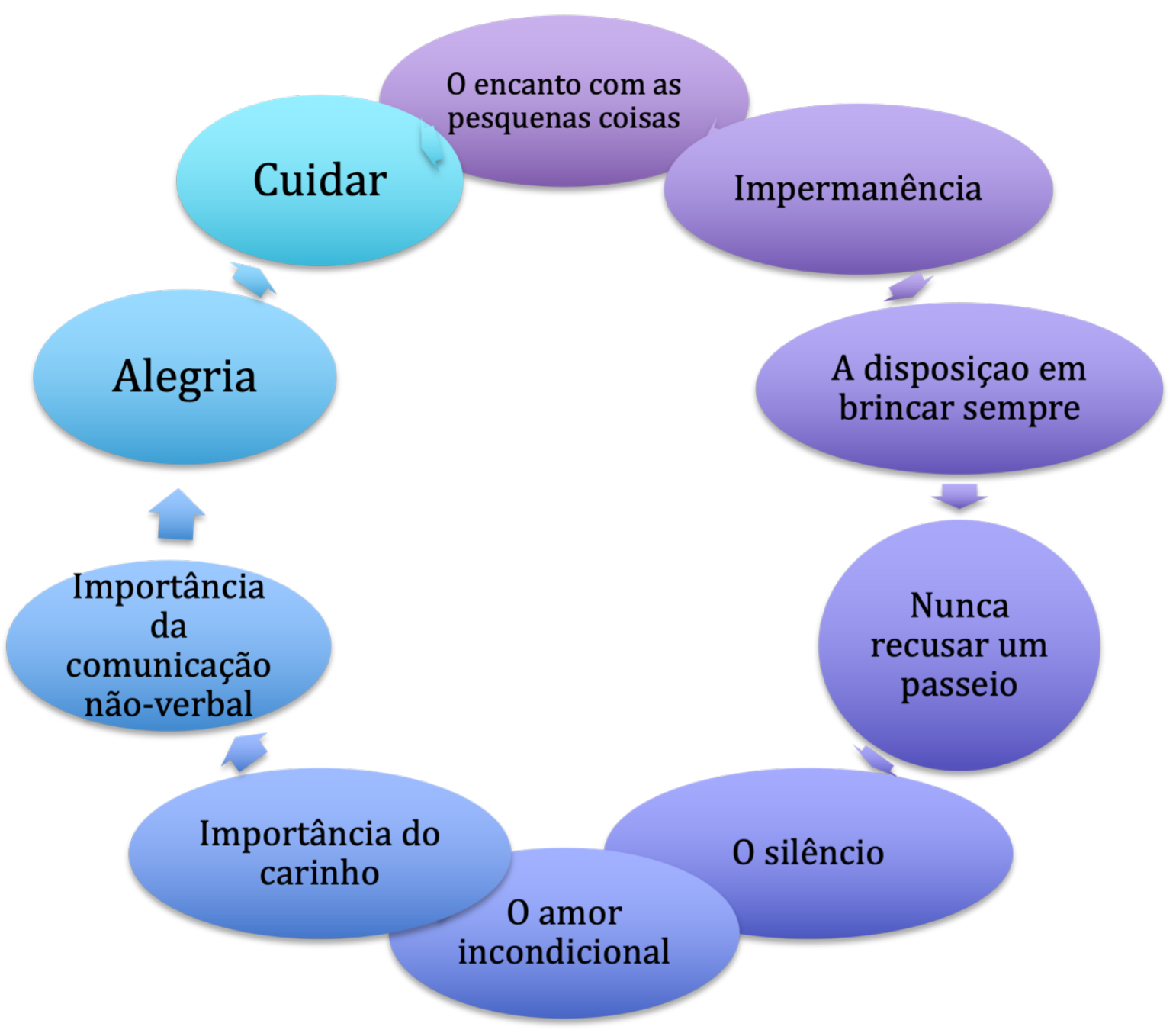

Gráfico elaborado por Tania Alice, jan./2021.

Durante o curso, ficou evidente a transformação das/os participantes e de seus animais, como se ocorresse uma abertura da sensibilidade e do olhar para o outro. Os animais se revelaram potentes cocriadores e incentivadores dessas descobertas ${ }^{10}$. Um dos recursos fundamentais que descobrimos e que estamos investigando atualmente é a telepatia animal, que nos permite ouvir o que o animal está nos dizendo. Anna Breytenbach, conhecida comunicadora animal, formada pelo Assisi International Animal Institute, EUA, explica que consegue se comunicar com todos os animais, especificamente com animais selvagens, para entender

${ }^{10}$ Os trabalhos criados pelas/os alunas/os e seus animais (gatos, cachorros, galinhas, tartarugas...) estão disponíveis em: https://www.instagram.com/petformances/ - @petformances. 
suas necessidades. Em seu documentário, intitulado Animal Communicator (2012), afirma: "Sofremos de uma profunda desconexão com a natureza. Minha intuição é que se aprendemos a ouvir os animais, aprendemos a curar a nós mesmos”11.

As técnicas que pesquiso atualmente ${ }^{12}$, junto à Profa. Dra. Sabina Secchin Scardua, têm uma abordagem que considero revolucionária, no sentido de permitirem a escuta dos animais por meio de técnicas de telepatia e comunicação, assim, literalmente, descentralizam, tirando o foco de nós, humanos, para abrir a percepção aos animais. Percebo que essas técnicas são fundamentais para a continuidade e desenvolvimento da pesquisa e, por isso, pretendo seguir a pesquisa e me aprofundar nesse tema.

Essas técnicas, acompanhadas de ampla bibliografia, estudos e experiências, propõem um deslocamento de nosso olhar, aquilo que Suely Rolnik (2019), em um de seus lembretes para uma constante descolonização do inconsciente, chama de "Ativar e expandir o saber ecoetológico ao longo da vida" (Rolnik, 2019, p. 195). A prática da Petformance propõe uma investigação minuciosa do comportamento animal, em especial dos 5 sentidos específicos de cada um dos animais participantes, além da exploração de diversas linguagens artísticas e do aprofundamento de uma conexão intensa com o animal. Como em projetos participativos, a Petformance propõe ações baseadas na escuta e na presença, ou seja, primeiro ouve-se as/os participantes e o espaço para, então, definir o projeto, não havendo, portanto, nada previamente determinado. Assim, desenvolve-se conhecimento significativo sobre as diferentes maneiras de criar arte com animais, partindo de experiências já realizadas e potencializando a criatividade deles. Gostaria de citar um trabalho inspirador, realizado pelo artista Christian Vieler, intitulado Petiscos no Ar, que capta a expressão de encanto de cachorros tentando apanhar um petisco no ar. O trabalho é uma forma de captar a intensidade da vida com o público animal, de forma a inspirar o público humano a estar atento ao que nos torna atentos, presentes e alegres.

${ }^{11}$ We suffer from a deep disconnection with nature. My intuition is that if we learn to listen to animals, we learn to heal ourselve. (Tradução nossa)

${ }^{12}$ Curso online de telepatia animal, de duração de 3 meses, proposto em formato online pela Profa. Dra. Sabina Secchin Scardua. 
Figura 9 - Petiscos no Ar

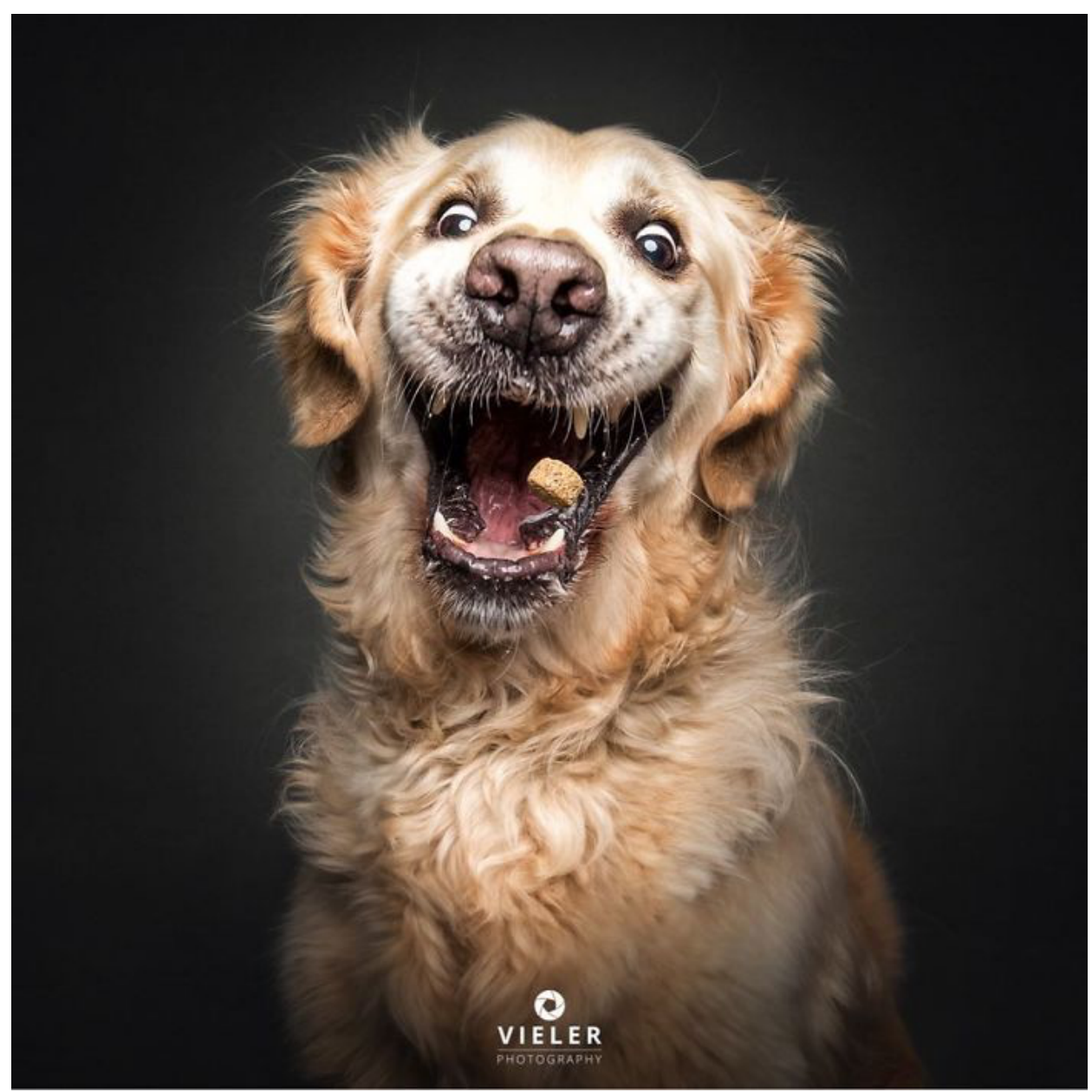

Fonte: Christian Vieler, 2015.

Concluindo, observo que a petformance descentraliza nosso olhar de uma perspectiva humana única, para dar voz aos animais através de técnicas ancestrais esquecidas. A experiência da petformance, aqui descrita por meio de procedimento cartográfico próprio à pesquisa em artes (Passos; Kastrupp; Escóssia, 2014), nos permite perceber que podemos aprender e nos conectar com o encanto e o amor através de todas as formas de vida e que não há circunstâncias que nos impeçam de fazer essa conexão. Abrindo mão da crença de que nós, humanos, temos o monopólio da criatividade, podemos nos abrir ao amor daqueles que nos fazem realizar impermanência, compaixão, meditação, silêncio e amor incondicional em todos os momentos do cotidiano.

Por fim, compartilho a reflexão de Simas e Rufino (2020, texto corrido online) 
Pergunta: como responder com vida a um sistema de desencanto? "O Brasil dos homens de bem", que invoca a espiritualidade colonial para a transformação do Estado em uma "bancocracia" vê na mortandade um impulso para o lucro.

É preciso ouvir o silêncio.

É fundamental soprar palavras de força, aprender o saber dos anciões da terra. Não basta colher a folha para fazer o remédio: é preciso saber cantá-la e encantá-la. Cantar a folha é reverenciar a permanência da árvore.

A Buda, ao gato Tom, aos animais e à natureza, dedico aqui, para finalizar, estes encantos e estas perspectivas.

\section{Referências}

ALICE, Tania. Performance como revolução dos afetos. São Paulo: Annablume, 2016.

ALICE, Tania. Manual para performers e não-performers. Rio de Janeiro: Editora Multifoco, 2020.

ANDERSON, Karen. Por que os gatos são assim? São Paulo: Publifolha, 2001.

BISHOP, Claire. Participatory Art and the Politics Spectatorship. London: Verso, 2012.

BOURRIAUD, Nicolas. Estética relacional. Trad. de Denise Bottmann. São Paulo: Martins Fontes, 2009.

DESPRET, Vinciane. Que diraient les animaux, si... on leur posait les bonnes questions? Paris: La Découverte, 2011.

FEITOSA, Charles. O silêncio dos animais. In. LINS, Daniel; OLIVEIRA, Nilson; BARROS, Roberto (Orgs.). Nietzsche/Deleuze: Natureza/Cultura. São Paulo: Lumme Editor, 2011.

HOOKS, Bell. O amor como a prática da liberdade: bell hooks.

(Love as the practice of freedom). Trad. para uso didático de Wanderson Flor do Nascimento, do original: Outlaw Culture. Resisting Representations. Nova Iorque: 
Routledge, 2006, p. 243-250. Disponível em: https://medium.com/enugbarijo/oamor-como-a-pr\%C3\%A1tica-da-liberdade-bell-hooks-bb424f878f8c].

JUNIOR, Moacir. Tentativas de capturar o sensível: a fotoperformance e as artes presenciais. Revista Concept. São Paulo, v. 7, n. 1, p. 92-101, jan./jun. 2018.

PASSOS, E.; KASTRUP, V.; ESCÓSSIA, L. (Orgs.). Pistas do método da cartografia: pesquisa intervenção e produção de subjetividade. Porto Alegre: Sulina, 2014.

KESTER, Grant. Conversation pieces: community and communication. In: Modern art. Los Angeles: California Press, 2004.

KRENAK, Ailton. A vida não é útil. São Paulo: Cia das Letras, 2020.

KRENAK, Ailton. Ideias para adiar o fim do mundo. São Paulo: Cia das Letras, 2018.

MASSUMI, Brian. O que os animais nos ensinam sobre politica. Trad. de Francisco Trento e Fernanda Mello. São Paulo: n-1 edições, 2017.

MBEMBE, Achille. Necropolítica. São Paulo: n-1 edições, 2018.

ROLNIK, Suely. Esferas da Insurreição: notas para uma vida não cafetinada. São Paulo: n.1 edições, 2019.

SERVIGNE, Pablo; CHAPELLE, Gauthier. L'entraide, une autre loi de la jungle. Paris: Les liens qui libèrent, 2017.

SIMAS, Luiz A.; RUFINO, Luiz. Encantamento: sobre política de vida. São Paulo: Morula, 2020.

TEIXEIRA, Renata. Performances do Encontro: práticas performativas em tempos de presença real e virtual. 2016. Dissertação (Mestrado em Artes Cênicas) Universidade Federal do Rio Grande do Sul, 2016.

PISA, João Paulo; TACITO, Jorge; LEME, Denise. A arte como instrumento de ensino de bem-estar animal. Revista Pubvet, v. 13, n. 7, p. 1-7, 2019.

WERÁ, Kaká Werá. História indígena do Brasil contada por um índio. São Paulo: Peirópolis, 1998.

\section{Referências filmográficas}

The Animal Communicator: what if you could talk to animals. Direção de Swati Thiyagarajan \& Craig Foster. Documentário. África do Sul: Natural History Unit Africa, 2012, 52 min. 
Petformances - Arte relacional como poéticas do cuidado para/com/por animais

Professor Polvo (My Octopus Teacher). Direção de Pippa Ehrlich \& James Reed. Documentário - Ciência e Natureza. África do Sul: Netflix, 2020, 85 min.

Recebido em: 03/04/2021

Aprovado em: 19/08/2021 